\title{
EL IMPERIO DEL BRASIL Y LA CUESTIÓN DEL PLATA: LA POLÍTICA EXTERIOR BRASILEÑA EN LA REGIÓN PLATINA DURANTE EL SEGUNDO REINADO
}

\section{Salvador Lima*}

Universidad del Salvador

$凶$ salvador.lima.89@gmail.com
Recibido: 1 de diciembre de 2020

Aceptado: 8 de julio de 2021

DOI: $10.46553 /$ colec.32.2.2021.p55-91

Resumen: A través de una revisión bibliográfica actual, el ensayo busca explicar el desarrollo de los acontecimientos y las ideas de la política exterior brasileña en el Río de la Plata, durante el reinado de Pedro II, a la luz de la historia regional, las instituciones y las tradiciones del Imperio, los intereses económicos de los grupos de presión y la política interna de la Corte y el Parlamento en Río de Janeiro. El trabajo pretende demostrar que las formas de intervención diplomática o armada del Brasil lograron impedir la reconstrucción del espacio del virreinato del Río de la Plata, gracias a una política exterior realista que gozaba de plena legitimidad entre las dirigencias y la intelectualidad del Imperio.

Palabras clave: Imperio del Brasil; política exterior; Río de la Plata; Triple Alianza

Abstract: By means of a study of the current bibliography on the subject, this essay seeks to explain the development of events and ideas on Brazilian foreign policy on

\footnotetext{
* Licenciado en Historia. Magister en Relaciones Internacionales. Investigador del GEHiGue (UBA/CONICET).
} 
the River Plate Basin, during the reign of Peter II, considering the regional history, the Imperial institutions and traditions, the economic interests of pressure groups and the domestic politics of the Court and the Parliament at Rio de Janeiro. The paper aims to demonstrate that the Brazilian forms of diplomatic or armed intervention managed to prevent the reconstruction of the space of the viceroyalty of the Rio de la Plata, due to a realistic foreign policy that enjoyed full legitimacy among the leaders and the intelligentsia of the Empire.

Keywords: Empire of Brazil; Foreign Policy; River Plate; Triple Alliance

\section{Introducción}

Para 1870, Brasil había logrado su maduración como Estado moderno, con un aparato burocrático-militar centralizado y una economía en expansión que le habían permitido mantener su integridad territorial, sofocar disidencias internas y ser reconocido como potencia rectora de la región. Como afirma Luiz Moniz Bandeira, este desarrollo político, tan distinto del momento en el que se hallaban las repúblicas rioplatenses, se debía al hecho de que "el Imperio del Brasil no era un simple sucesor del Estado portugués. En verdad, era el propio Estado portugués" (Moniz Bandeira 2006). Según el autor, en 1808, la monarquía de los Braganza había encontrado una nueva base geográfica, ajustándose a sus condiciones económicas y sociales y sentando las bases para la prolongación dinástica e institucional de 1822 y la continuidad de tradiciones y objetivos del nuevo Imperio (Moniz Bandeira 2006). A partir de entonces, la corona imperial y las repúblicas platinas heredaron el conflicto que sus metrópolis europeas habían prolongado durante trescientos años. Conocido genéricamente entre los brasileños como la Questão do Prata o Questões Platinas, se trató de una serie de intervenciones armadas, diplomáticas y económicas que el Brasil monárquico llevó a cabo en la cuenca del Plata para impedir la construcción de un gran estado que, imitando la territorialidad del virreinato del Río de la Plata, pudiese amenazar un equilibrio regional favorable al Imperio (Jardim 2011). La finalidad del trabajo ha sido realizar un recorrido 
bibliográfico para explicar cómo la política exterior del Imperio del Brasil con las repúblicas de Buenos Aires, Montevideo y Asunción habría estado atravesada por la historia de interdependencia regional entre las provincias rioplatenses y el sur del Imperio, así como por factores internos brasileños, tales como la política doméstica y la ideología imperial.

La literatura sobre la historia de las relaciones exteriores del Imperio del Brasil es bastante amplia. Cabe mencionar, en primer lugar, a Francisco Doratioto, probablemente el historiador más prolífico en cuanto a los encuentros y desencuentros brasileños y rioplatenses durante el siglo XIX, especialmente la Guerra de la Triple Alianza y sus consecuencias en el equilibrio de poder regional $(1999,2002,2008)$. En la misma línea de interpretación de Doratioto, Leslie Bethell (1996) y Moniz Banderia (2006) han explicado las intervenciones del Brasil en el Río de la Plata como la consecuencia última de un proceso histórico de larga duración en la definición de los espacios estatales-nacionales en el Cono Sur. El propio Bethell (1990) y John Lynch (1990) también hacen referencia a la presión de los magnates de Río Grande do Sul sobre la política exterior imperial y sus amenazas de secesión como factor explicativo de la propensión brasileña a actuar por la fuerza o por la diplomacia en el Río de la Plata. Dentro de esta perspectiva, Gabriela Nunes Ferreira ve una relación de continuidad entre la provincia de Rio Grande do Sul y el Estado Oriental, los cuales habrían formado una misma unidad territorial, con un sistema propio de relaciones políticas clientelares que habría funcionado como un canal de transmisión de los problemas platinos dentro del Imperio del Brasil (Ferreira 2006). En el mismo sentido, Cesar Augusto Guazzelli explica la Revolução Farroupilha a través de los vínculos políticos, tratados, convenciones e intereses complementarios entre los magnates rurales de Rio Grande do Sul, el Uruguay y las provincias del Litoral argentino (Guazzelli 2015). Desde un punto de vista más socio-económico, Keila Grinberg explica cómo el entramado social de la frontera brasileña-uruguaya, con toda su red de intereses pecuniarios, lazos familiares, fugas de esclavos y derechos de propiedad, se hallaría una fuente crucial de conflicto para comprender los problemas de las relaciones internacionales entre los estados del Plata (Grinberg 2019). Respecto al cuerpo general de la historia de la política exterior imperial, Amado Luiz Cervo y Clodoaldo Bueno (2015) y su enfoque realista han servido como columna vertebral para comprender la 
filosofía política del Segundo Reinado (1840-1889) en torno a los conceptos del cálculo de poder y la seguridad. Por otro lado, las biografías en Brazilian Diplomatic Thought. Policymakers and Agents of Foreign Policy (17501964), proyecto conjunto editado por la Fundação Alexandre de Gusmão, han brindado un claro acercamiento al pensamiento político de los notables hombres de estado brasileños del siglo XIX (Pimentel 2016). Más recientemente, César Barrio ha señalado la dimensión ideacional de la política intervencionista del Brasil en el Río de la Plata, la cual habría sido la manifestación externa de la propia identidad política del Partido Conservador o saquarema y de ciertas "fuerzas profundas" que lo arrastraban hacia la tradición intervencionista lusitana en el Río de la Plata (Barrio 2018).

Teniendo en cuenta estos antecedentes, el trabajo propone una exposición ordenada sobre la Cuestión del Plata, incluyendo las consideraciones geográficas más estructurales, los intereses económicos de los actores regionales, la influencia de factores de la política interna brasileña y el peso de la historia en las relaciones del Brasil con sus vecinos de habla castellana. Siguiendo a los autores consultados, la política exterior del Imperio del Brasil, al menos hasta los años posteriores a la Guerra del Paraguay, habría estado influenciada por las relaciones transnacionales entre los magnates de Rio Grande do Sul y sus pares de las provincias rioplatenses, así como por la determinación imperial de impedir la reconstrucción del virreinato rioplatense, asumido como una verdadera vocación por la monarquía bragantina con la finalidad de asegurar su integridad territorial y sus pretensiones de dominio continental. Como se verá, la obra no pretende ser un ejercicio de historia de las ideas, sino llamar la atención sobre la complejidad de los hechos diplomáticos, su compenetración con la política interna del Imperio y su conexión con las ideas tradicionales del Segundo Reinado.

En cuanto al orden de las ideas a exponer, el primer capítulo del artículo describe la construcción del Estado brasileño, considerando el pasado colonial portugués, la proyección americana de la corte de los Braganza, las limitaciones de las primeras décadas de reinado de Pedro I y las revueltas regionales, para cerrar con la formulación del poder central y la imposición de la hegemonía brasileña en el Río de la Plata. En el segundo capítulo, se analiza el sistema de ideas de legitimación creado a favor del 
concepto imperial, ya que sus exponentes y sus principios elementales formaron parte del aparato de creencias que colocaban al Brasil en contra de las repúblicas del Río de la Plata. Luego, en el tercer capítulo, el artículo retoma la narrativa de los hechos posteriores a la caída de Rosas, explicando la articulación entre la inestabilidad en el Río de la Plata, los intereses riograndenses y la alta política del Imperio, para desembocar en la Guerra de la Triple Alianza. El cuarto capítulo recupera algunos conceptos importantes del choque de ideas y de partidos políticos en el Imperio, provocados por el propio desarrollo económico y social del país y sus consecuencias en la política exterior. Finalmente, en la última parte se describe la lucha del gabinete imperial por impedir la expansión territorial argentina, de acuerdo con los principios de interés nacional y hegemonía brasileña explicados en apartados anteriores, para dar paso a las consideraciones finales del trabajo.

\section{La construcción del Estado imperial}

Para 1831, una combinación de desaciertos políticos de parte del primer emperador brasileño, Pedro de Braganza, produjo el clima de descontento militar y político, protestas y violencia callejera que lo empujó a la abdicación. La sanción unilateral de la Constitución centralista de 1824, la influencia de la facción portuguesa en la Corte, los claudicantes tratados con Gran Bretaña, la mal dirigida Guerra Cisplatina y, por último, el estilo absolutista y la nostalgia lusitana del monarca causaron su extrañamiento entre la elite local y los sectores populares del recientemente declarado Imperio del Brasil. Según Bethell, su exilio simbolizó el quiebre definitivo con Portugal y la nacionalización del trono, concluyendo el proceso de independencia (Bethell 1990). A partir de entonces, el Imperio entró en su etapa más parlamentaria y federalista. Los dueños de la nueva situación eran líderes liberales moderados como Bernardo Pereira de Vasconcelos, Diogo Feijó y Evaristo de Veiga, miembros de la heterogénea coalición de fuerzas políticas y sociales que había favorecido la independencia, pero que se habían opuesto a la extrema centralización y reflejos absolutistas de Pedro. Aunque esta elite de letrados, terratenientes y hombres de negocios adhería vagamente a los principios del liberalismo, reconocía en la monarquía el 
mecanismo para sostener la esclavitud, fundamento del régimen económico que colocaba en la cúspide de la sociedad a los señores de la tierra y los grandes comerciantes urbanos (Mattos 2003). Por estos motivos, el liberalismo de los políticos brasileños fue muy moderado, centrando su programa de reformas en cuestiones administrativas, que minaban la autocracia centralista, pero que no atacaban las bases oligárquicas del Imperio. Además de la creación de la Guardia Nacional y el empoderamiento de los jueces de paz, instituciones que favorecían a las elites provinciales en detrimento de la Corona, en 1831, el Parlamento creaba la figura del Regente, que gobernaría con poderes ejecutivos limitados, en nombre del emperador-niño Pedro II, pero sin ejercer el Poder Moderador que le daba la Constitución. Por otro lado, el Ato Adicional de 1834 abolió el autoritario Consejo de Estado, confirió amplias prerrogativas a las asambleas provinciales y acordó un sistema de rentas compartidas entre el gobierno imperial y las provincias. Con todo, aunque los gabinetes liberales rigieron el Imperio hasta 1837, las reformas no habían alterado las bases socioeconómicas del Antiguo Régimen, sino que solo habían permitido a los magnates provinciales fortalecerse como déspotas locales al retraerse el Estado central. Significativamente, el efecto último de los cambios de 1831-1834 fue el estallido de una serie de revueltas regionales, durante la década de 1830, desconectadas entre sí e impulsadas, generalmente, por demandas liberales, como la autonomía provincial, la abolición de la esclavitud, la democracia o la separación de la Iglesia del Estado. Entre todas las "revoluciones" de provincias, especial mención merece la Revolução Farroupilha, la cual sostuvo la secesión de la República de Rio Grande do Sul, entre 1836 y 1845, provincia cuya historia estaba íntimamente ligada al antiguo expansionismo lusobrasileño en la frontera del Río de la Plata.

Desde la Restauración portuguesa de 1668 y durante todo el siglo XVIII, la Corte de Lisboa había alentado las penetraciones en territorio hispanoamericano, el contrabando con los comerciantes españoles y las fundaciones de puestos de frontera, causando protestas diplomáticas y conflictos armados de tropas coloniales que, si bien muchas veces tenían su propia lógica local, los monarcas lusitanos los solían articular con las guerras europeas para equilibrar una balanza de fuerzas ibéricas que tendía a ser favorable a España (Marchena Fernández 2015). Tras un largo período 
de invasiones mutuas, expediciones de castigo y guerras propiamente dichas en el escenario rioplatense, la firma del tratado de San Ildefonso, en 1777, puso un alto a las disputas luso-españolas y estableció las fronteras entre sus territorios sudamericanos. Sin embargo, tras el estallido de las guerras revolucionarias, en 1792, y el reinicio de la rivalidad anglo-francesa, la paz entre las coronas ibéricas volvió a verse interrumpida. Para 1810, con el virreinato del Río de la Plata en descomposición, el príncipe-regente Juan de Braganza, residente en Río de Janeiro desde 1808, podía suponer algún tipo de protectorado sobre las provincias rioplatenses, con o sin la aquiescencia de los criollos españoles. Las aspiraciones americanistas de Juan no eran una veleidad personal, sino que se acoplaban bien con ciertas corrientes de la Corte lusitana que, desde finales del siglo XVIII, veían en el Brasil el futuro de la monarquía Braganza (Bethell 1985). De hecho, aprovechando las conmociones vividas en Buenos Aires, entre 1806 y 1810 , el príncipe-regente había apoyado silenciosamente las pretensiones legitimistas de su esposa Carlota de Borbón sobre el virreinato platino, así como había estimulado los planes de algunos miembros del Directorio de las Provincias Unidas para nombrarlo Emperador de América (Moniz Bandeira 2006). Luego, Juan mostró toda su proyección americana al tomar la decisión de mantener a la Corte en Río de Janeiro, tras la desocupación francesa de la península, en 1814. Poco después, en diciembre de 1815, elevaba al Brasil a la categoría de Reino en paridad de condiciones con Portugal y, en 1817, ordenaba la ocupación definitiva de la Banda Oriental, la cual se convirtió en la provincia Cisplatina, en 1821.

Tampoco habría que menospreciar las pretensiones de los hacendados y comandantes de frontera gaúchos a la hora de diseñar la política imperial en la Banda Oriental. La prosperidad de Rio Grande do Sul se sustentaba en la riqueza ganadera y el procesamiento de charque y las condiciones históricas de su poblamiento y los conflictos fronterizos en la Banda Oriental habían conducido a una estructura social y económica en la cual la clase propietaria ejercía el mando militar de las tropas de frontera (Bethell 1990). En 1817, los comandantes gaúchos fueron la punta de lanza de la anexión portuguesa de la provincia Oriental y la aprovecharon para comprar tierras y establecer ganado en dicha provincia. Tras la derrota en la Guerra Cisplatina y la independencia uruguaya de 1829, aunque no perdieron sus títulos de propiedad y el contrabando de animales nunca se detuvo, los magnates 
brasileños ya no pudieron contar con la industria charqueadora de Montevideo, quedando obligados a comercializar el ganado en los puertos riograndenses y pagar los altos aranceles del Estado imperial (Bethell 1990). De este modo, la provincia de Rio Grande do Sul quedó atrapada en una situación particular, ya que, aunque integraba el Imperio y se subordinaba a la autoridad central, su posición geográfica, sus tradiciones militares y su perfil ganadero exacerbaban las fuerzas centrífugas que la acercaban a los conflictos políticos del Río de la Plata (Ferreira 2006). De hecho, las estrechas relaciones políticas e intereses complementarios de los magnates gaúchos con los caudillos en Uruguay y en las provincias argentinas del Litoral fueron factores importantes en su decisión de rebelarse y declarar la República de Rio Grande do Sul, en 1836 (Guazzelli 2015). Según Bethell, el líder de la Revolução Farroupilha, Bento Gonçalves da Silva, habría buscado un arreglo con Juan Antonio Lavalleja y Juan Manuel de Rosas para formar una organización política confederada que se adaptase mejor a los intereses ganaderos riograndenses (Bethell 1990). Eventualmente, si estos planes nunca pudieron concretarse fue debido a la lealtad monárquica de las ciudades costeras de la provincia, cuyas actividades comerciales dependían de la conexión con Río de Janeiro, la cooptación de ciertos líderes revolucionarios por parte del Ejército Imperial y la imposibilidad de encontrar apoyos políticos sostenibles en las convulsas provincias del Río de la Plata (Bethell 1990).

El mayor efecto del conjunto de revueltas regionales fue provocar un reagrupamiento de fuerzas conservadoras en Río de Janeiro que restauraron la autoridad central del Imperio para evitar su disgregación. En 1838, una alianza entre magistrados imperiales, intelectuales y terratenientes gestó el primer atisbo del Partido Conservador, el cual, bajo la égida de la regencia de Pedro de Araújo Lima, formó un gabinete de burócratas de mentalidad nacional, cuya idea madre era que el país no estaba listo para un sistema liberal, de modo que había que asegurar el orden social y la unidad imperial mediante un fuerte gobierno central (Bethell 1990). Por otro lado, la recreación de la autoridad nacional también debe ser relacionada con la expansión de la producción cafetalera en el valle del Paraíba, ya que los crecientes ingresos de su exportación permitieron incrementar el aparato burocrático-militar adecuado para vencer o cooptar a las elites regionales (Sodré 1983). De manera gradual y negociada, el Estado y los grandes jefes 
provinciales fueron tejiendo unos lazos de mutuo interés y beneficio, a través de los cuales el primero garantizaba el mantenimiento del orden social, honores nobiliarios y cargos públicos, y los segundos ponían sus redes clientelares al servicio del Imperio (Graham 2003).

En términos institucionales, la recentralización se formalizó, en 1840, con la ley de interpretación del Ato Adicional, con la cual se restauró el Poder Moderador del emperador y se fortalecieron las prerrogativas del gobierno central. En el mismo año, preocupada por el regresso aristocrático, la minoría liberal en el Parlamento, apoyada por sectores del ejército y de la burocracia, aceptó conceder la mayoría de edad a Pedro II, de 15 años, para deshacer el gobierno de Araújo Lima. Sin embargo, dada la juventud del emperador, el resultado fue una crisis de autoridad que, para 1841, permitió la formación de un nuevo gabinete conservador. A continuación, la mayoría conservadora en el Parlamento restauró el Consejo de Estado y colocó en manos de los ministros del Palacio de San Cristóbal el control absoluto sobre toda la estructura administrativa y judicial del Brasil. La restauración del poder central, solventada por la prosperidad de la economía cafetalera y legitimada por la victoria sobre todas las revueltas regionales, permitió la adopción de una política exterior común y autónoma que aglutinase a todas las fuerzas centrífugas del Imperio y que proyectase, a largo plazo, sus intereses nacionales (Cervo y Bueno 2015). La misma estaría definida por: el rechazo a las relaciones asimétricas con Gran Bretaña, el mantenimiento del tráfico negrero, el intervencionismo en el Río de la Plata y la defensa de la integridad territorial del Imperio (Cervo y Bueno 2015). En efecto, la presión del Foreign Office contra el tráfico indujo a los miembros de la aristocracia esclavista y a la burguesía comercial a cerrar filas y ver en la unidad del Imperio la mejor manera para defender la base de todo su régimen socioeconómico (Mattos 2003). Al mismo tiempo, a medida que se profundizaba el giro interior del Imperio hacia su zona del centro-sur, se hacía cada vez más imperante garantizar la seguridad en las fronteras con las repúblicas vecinas y la libre navegación de los ríos platinos para conectar el interior brasileño con el Atlántico (Sodré 1983).

La pacificación de Rio Grande do Sul, en 1845, se enmarcaba en dicha cuestión fronteriza. Después de todo, la paz entre las fuerzas imperiales y los farrapos consistió en un acuerdo tácito, según el cual la provincia meridional volvía al seno del Imperio y el Estado brasileño se comprometía 
a proteger sus intereses ganaderos en la región rioplatense y rebajar los aranceles portuarios (Bethell 1990). La reconciliación entre las elites imperiales y gaúchas no había sido solamente una mera cuestión fraternal, sino que ambos grupos la habían buscado debido al curso que tomaba la Guerra Grande en Uruguay, conflicto iniciado en 1838 como una más de las desavenencias entre los caudillos orientales, pero que en poco tiempo pasó a entrecruzarse con las guerras civiles argentinas y la propia Revolução Farroupilha. Si bien el Imperio había evitado intervenir directamente en la guerra oriental, luego encontró en ella una oportunidad para incorporar a los comandantes gaúchos a la causa imperial, ya que el conflicto se volvía favorable para Manuel Oribe, líder de un Partido Blanco hostil a los ganaderos brasileños y apoyado por los soldados de Juan Manuel de Rosas (Corrêa 2016). En 1845, el presidente del gobierno del Cerrito había ordenado la expropiación de los bienes de los exiliados unitarios, así como las haciendas, el ganado y los esclavos de los súbditos brasileños, matando o apresando a sus dueños. La violencia de Oribe contra los magnates gaúchos de la frontera produjo la protesta de los parlamentarios de Rio Grande do Sul en la Corte, donde reclamaron la reacción militar del Imperio, así como las incursiones particulares o californias de los comandanteshacendados de la frontera (Torres 2011). El otro motivo de hostilidad entre los magnates gaúchos y los orientales era el hecho de que éstos acogían a los esclavos fugitivos brasileños, que se volvían hombres libres en territorio uruguayo, desde que la esclavitud había sido abolida definitivamente por Oribe en 1846 (Grinberg 2019). Ahora bien, si los caudillos-estancieros del Partido Blanco eran los mayores rivales de farrapos, el gobernador de Buenos Aires era la verdadera "bestia negra" de los estadistas imperiales, quienes veían, en sus posiciones respecto a las repúblicas platinas, la intención de reconstruir el viejo espacio virreinal del Río de la Plata (Moniz Bandeira 2006).

En 1843, las relaciones entre el gobierno imperial y la Confederación se habían roto, debido al doble juego de Rosas, quien, inicialmente, había otorgado muestras de querer conformar una alianza con el Imperio para pacificar la región uruguaya-riograndense, para luego rechazar los invites brasileños, una vez que Oribe consolidó su posición en el sitio de Montevideo. De hecho, ante la injerencia porteña en Uruguay, en 1844, el gabinete liberal intentó practicar una "política de provocaciones sabiamente 
dosificadas", consistente en formar una alianza militar con Gran Bretaña, Francia, Paraguay, Entre Ríos y Corrientes para derrocar al gobernador de Buenos Aires (Doratioto 2008). El fracaso en formar dicha coalición y la anunciada retirada de las potencias europeas, tras su pírrica victoria en las aguas del Paraná, combinada con la derrota de la última revuelta liberal en Pernambuco, en 1848, provocó la caída del gobierno y marcó la necesidad de un cambio institucional. En ese año, Pedro II creó la figura del presidente del gabinete de ministros y se la otorgó al veterano Araújo Lima, nombrado marqués de Olinda, quien volvió a formar un gobierno conservador (Bethell 1990). Entre ellos, el ministerio de Relaciones Exteriores fue asumido, en 1849, por Paulino Soares de Souza. Éste creía que, una vez retirado el dinero francés de Montevideo, la victoria de Oribe sería inevitable e implicaría la anexión de Uruguay a la Confederación, a la que de seguro le seguiría Paraguay y Bolivia. Paulino no dudaba que, si Rosas lograba recrear la "Gran Argentina", su poder se vería tan incrementado que no dudaría en "vir sobre nós com forças e recursos maiores, que nunca teve, e envolvernos em uma luta em que havíamos de derramar muito sangue e despender somas enormes" (Doratioto 2008, 227). Desde el Palacio de Itamaraty, Paulino redefinió la política exterior imperial y tejió las redes necesarias para destruir al gobernador de Buenos Aires y cumplir los objetivos de Brasil, de acuerdo con la herencia portuguesa y los intereses imperiales (Ferreira 2016).

La herencia portuguesa no era otra que las fronteras del Brasil. Desde la independencia, la validez del uti possidetis como principio realista en la fijación de límites fue afirmándose lentamente y no sin obstáculos. Aunque el pionero en recuperarlo como base legal fue Duarte Ponte Ribeiro, negociador brasileño en las tratativas de límites con las repúblicas del Pacífico, su elevación a política de Estado se debió a Soares de Souza, quien lo transformó en la espina dorsal de toda la doctrina limítrofe del Imperio y sentó un precedente que sus sucesores defenderían con intransigencia (Torres 2011). El razonamiento de Paulino era que el problema de las fronteras entre el Imperio y las repúblicas no podía basarse en los tratados hispano-portugueses, por lo tanto, lo más razonable era adoptar el uti possidetis, ya que se basaba en una política de cálculos realistas, no en veleidades jurídicas imposibles de concretar (Goes Filho 2013). El uti possidetis era un argumento que se amoldaba a los debates internos del 
Imperio, ya que se asentaba en bases históricas, daba tranquilidad a las almas culposas y silenciaba a las voces extremistas que pedían un expansionismo desmedido (Cervo y Bueno 2015). Además, funcionaba como un paquete jurídico muy adecuado para los intereses del Estado más poderoso, ya que formalizaba en el papel los hechos consumados por la conveniencia y por la fuerza.

Esta política exterior realista quedó patente ante las diferentes posturas tomadas en el Amazonas y el Río de la Plata. En el primero, sobre el cual el Imperio tenía la soberanía de sus dos orillas y todo su caudal hasta la frontera con las repúblicas andinas, los brasileños sostuvieron, hasta 1864 , su derecho inalienable a gestionar la navegación de barcos extranjeros (Reis 2001). Por el contrario, en el caso del Río de la Plata, Brasil adoptó los mismos argumentos librecambistas que rechazaba para el Amazonas. Desde la perspectiva brasileña, la libre navegación de los ríos clientes de la cuenca del Plata era necesaria para resolver el aislamiento de la inaccesible zona del Mato Grosso. De ahí la obstinación de Soares de Souza en sostener la independencia de Uruguay y Paraguay, ya que su calidad como países soberanos afirmaba el carácter internacional de los ríos interiores, haciendo de su libre navegación un imperativo de derecho de gentes. Al mismo tiempo, la existencia de los dos estados-tapón era funcional para la hegemonía regional del Brasil, dado que, gracias a ellos, el Imperio evitaba compartir una extensa y disputada frontera con la Confederación Argentina y, si la política exterior se manejaba con mesura, podía mantenerlos bajo su sombra. Siguiendo los lineamientos del vizconde de Uruguai, desde 1849 hasta 1864, la política exterior del Brasil en la cuenca del Plata consistió en un intervencionismo consistente, sea militar, económico o diplomático, en aras de impedir la aglomeración de los estados platinos y mantener el equilibrio regional favorable al Imperio (Barrio 2018).

A la luz de esta lógica, se comprende por qué la intervención militar porteña en la guerra civil uruguaya y la negativa de Rosas a reconocer la independencia paraguaya alarmaba a políticos como Paulino. En efecto, al ministro de Itamaraty ya no le interesaba reparar las relaciones con la Confederación, sino que todos sus movimientos diplomáticos se dirigieron a provocar la guerra con Rosas, empezando por el retiro de la legación imperial de Buenos Aires, el reconocimiento brasileño de la independencia paraguaya y el desconocimiento de Oribe como presidente de la república 
oriental (Ferreira 2006). La determinación de Paulino habría encolerizado a Rosas, quien ordenó a su ministro en Río de Janeiro, Tomás Guido, exigir reparaciones diplomáticas a favor de Oribe, utilizando la amenaza de guerra, si fuese necesario (Torres 2011). Desde 1850, tras la partida de las fuerzas europeas de Montevideo, Paulino apuntaba a crear una trama de alianzas para aislar al gobernador de Buenos Aires y derrotarlo con la menor intervención posible del Ejército Imperial. Ciertamente, utilizar las propias discordias rioplatenses era mucho más económico que una intervención directa y evitaba al Imperio la incomodidad de ser acusado de amenazar la independencia uruguaya (Moniz Bandeira 2006). En primer lugar, Paulino logró que el Parlamento brasileño aprobase la Ley Eusébio de Queiroz de extinción del tráfico de esclavos, en septiembre 1850, para así paliar las relaciones con Gran Bretaña, envenenadas a raíz de la persistencia del contrabando de africanos en el Atlántico sur y las acciones de la Royal Navy, refrendadas por la Aberdeen Act, contra los traficantes de bandera brasileña (Cervo y Bueno 2015). Por otro lado, autorizó al banquero gaúcho Irineu Evangelista de Souza a expedir voluminosos préstamos a los aliados rioplatenses y nombró a Honório Hermeto Carneiro Leão como ministro plenipotenciario en Montevideo para establecer acuerdos con el gobierno de la ciudad asediada y las provincias de Corrientes y Entre Ríos, lideradas por Justo José de Urquiza (Corrêa 2016).

La misión de Honório es considerada uno de los grandes triunfos de la historia diplomática brasileña, ya que logró articular una alianza regional que cerró un conflicto que amenazaba la integridad territorial del Imperio, sin involucrar un gran esfuerzo militar de su parte (Torres 2011). Considerando que la política fiscal "porteñista" de Rosas ya había creado las condiciones para su propio derrocamiento dentro de la Confederación Argentina, al erosionar la tolerancia de las clases propietarias del Litoral, la "diplomacia de los patacones" de Evangelista de Sousa y la habilidad de Honório para explotar las grietas internas entre las provincias argentinas dieron a Urquiza el pequeño empujón que necesitaba para convertirse en el ariete contra Rosas (Moniz Bandeira 2006). La victoria en la batalla de Caseros, el 3 de febrero de 1852, fue una auténtica victoria diplomática e incluso militar del Imperio, punto culminante de la política exterior de Paulino Soares de Souza (Ferreira 2006). Rosas y su supuesto proyecto de anexión del Uruguay y el Paraguay quedaron erradicados, mientras que el 
acuerdo con Urquiza garantizaba para el Brasil la libre navegación de los ríos internos. En cuanto a la República Oriental, con una serie de tratados firmados por Andrés Lamas en Río de Janeiro, en 1851, Brasil reafirmó su condición de "protector" de la independencia uruguaya y, a cambio, el gobierno de Montevideo eliminó todos los impuestos al retiro de ganado oriental por parte de los estancieros gaúchos, legalizó la propiedad de éstos sobre cerca del 30\% del territorio uruguayo, estableció la extradición de esclavos fugitivos, fijó los límites territoriales según las aspiraciones brasileñas e hipotecó los ingresos de la aduana de Montevideo y las rentas del Estado al Brasil, a cambio de unos préstamos por tiempo indeterminado. Si Uruguay no se volvía una provincia brasileña, era lo más parecido a una.

\section{La ideología monárquica}

Tras la victoria sobre Rosas, Honório Carneiro Leão fue nombrado vizconde de Paraná y primer ministro, mientras que Paulino Soares de Souza obtuvo el título de vizconde de Uruguai y mantuvo la cancillería. Juntos, formaron un gabinete de Conciliação que institucionalizó el consenso tácito entre liberales y conservadores. Esta conciliación entre los partidos era posible debido a su carácter inorgánico. De hecho, los grupos parlamentarios no tenían unidad, no dependían de la competencia electoral para alcanzar el poder, ni representaban ideologías antagónicas definidas (Graham 1990). Hasta 1850, solamente la legitimidad de la monarquía, la esclavitud y el principio jerárquico habían sido las ideas generalmente compartidas entre las clases superiores $y$, aunque ello no impedía excepciones (como el republicanismo en Río Grande), ni implicaba sentimientos de "brasilidad", se explicaba más por la inercia de la fidelidad a los vínculos tradicionales (Carvalho 2003).

La identidad brasileña, como todas las comunidades imaginadas en el siglo XIX, fue una construcción cultural de la clase gobernante del Imperio para transferir las lealtades políticas provinciales a la imagen de nación, a través de la invención de un paquete ideológico propio que respondía a los intereses del Estado (Carvalho 2003). Para este cometido, fue imprescindible la fundación del Instituto Histórico y Geográfico Brasileño, en 1838, a través del cual el Estado aglutinó a sus pensadores y construyó 
la identidad nacional (Carvalho 2003). Siguiendo las tendencias de la historiografía francesa, el Instituto tenía como preocupación principal dotar a la nación brasileña de un sentido espiritual, esencialista y orgánico y promover una historia al servicio del Estado (Prado 2001). Abrazando una concepción positivista de la historia, los trabajos del IHGB situaban a la monarquía constitucional de Pedro II como el agente del avance de la ciencia y como la evolución lógica de un proceso histórico lineal vinculado al progreso de la civilización (Guimarães 1988). En su exaltación del Imperio, la producción del IHGB buscaba desalentar a las minoritarias voces democráticas dentro del Imperio, vinculando a la monarquía con el pasado portugués y la Europa ilustrada y contrastándola con la aplicación inmadura y viciosa del régimen republicano en los países vecinos (Guimarães 1988). Según esta visión, Brasil contaba con Pedro II, quien hacía de monarca ilustrado y prudente, garante de la imagen civilizada del país en el exterior y del mantenimiento del orden y la integridad en el interior (Mattos 2003).

Dado que la protección de estos valores peligraba si se contagiaba la anarquía republicana a través de las porosas fronteras del Imperio, la retórica de los historiadores se ocupó plenamente de la defensa de los límites brasileños. Entre ellos, Francisco Adolfo de Varnhagen fue el gran abogado del uti possidetis y uno de los responsables, junto con el diplomático Duarte da Ponte Ribeiro, de su teorización como política de Estado. Sus respectivas labores produjeron una gran colección de tratados y estudios sobre el uti possidetis y los derechos territoriales del Imperio, que sería utilizada por el vizconde de Uruguai para dotar de mayor sutileza doctrinaria a una política exterior activa en el Río da la Plata, que tendría continuidad hasta la Guerra del Paraguay. Según César Barrio, la etapa intervencionista habría sido un momento hobbesiano en la proyección regional del Brasil, una síntesis ideacional entre la dimensión externa del ideario del Partido Conservador dominante en la Corte y unas "fuerzas profundas" de naturaleza axiológica, arraigadas en la longue durée, que habrían condicionado las relaciones internacionales del subsistema platino (Barrio 2018). Sin eliminar del cuadro las relaciones transnacionales y los intereses económicos entre la sociedad rural del sur brasileño y las provincias rioplatenses como factor de conflicto, la realpolitik brasileña, inaugurada por el vizconde de Uruguay y continuada por sus sucesores hasta el vizconde de Rio Branco, habría estado 
fundamentada en motivos ideacionales, morales e históricos que sirvieron como armazón espiritual para la política del poder del Partido Conservador, en el ámbito doméstico y el internacional, a la vez (Barrio 2018). En cierta medida, sería posible vincular esta política intervencionista con la historia oficial de Varnhagen, en la cual Brasil era el heredero portugués que venía a restaurar y proteger las "fronteras naturales" en el Amazonas y el Río de la Plata, frente a los ultrajes y usurpaciones de los españoles y su prole republicana (Prado 2001). La idea era muy cómoda para la construcción ideológica de la nación, ya que creaba la ilusión del Brasil-Isla, un territorio nacional permanente, prehistórico, indivisible, cuya unidad como nación estaba entonces bendecida por la naturaleza y su propia grandeza (Santos 2016). A través del IGHB, el Estado brasileño buscaba asentarse en la tradición intelectual europea, integrando lo viejo y lo nuevo, e incluía al Imperio dentro del concierto de "naciones civilizadas" (Santos 2016).

La gran incongruencia insalvable del Brasil con el ideario moderno europeo era la esclavitud. El interés en mantener la mano de obra servil había sido un importante elemento aglutinador de la aristocracia, ya que era la base del régimen económico y las presiones abolicionistas británicas proveían a los terratenientes esclavistas y a los grandes comerciantes asociados a ellos de una causa nacional con la cual cerrar filas. De hecho, gracias a la elasticidad del liberalismo del siglo XIX, los escritores del IGHB supieron encontrar algunas argucias bien argumentadas para justificar la mano de obra forzada en un país que se proclamaba el representante de la civilización en América (Salles 2013). Pintando a la esclavitud como un mal necesario y un hecho económico de la Modernidad, los cuestionamientos quedaban contrabalanceados por consideraciones humanitarias, históricas, pragmáticas, jurídicas y biológicas (Salles 2013). Detrás de los recursos teóricos había una necesidad de adaptar la doctrina a realidades sociales que no podían prescindir abruptamente de la esclavitud sin provocar grandes conmociones internas.

\section{EI Tratado de la Triple Alianza}


La hegemonía de facto del Brasil, ganada en 1852, no logró terminar con la conflictividad en el Río de la Plata, ya que la caída de Rosas no eliminó la rivalidad entre las facciones y las provincias. En primer lugar, la secesión porteña de la Confederación Argentina presagiaba un escenario de guerra. Aunque había en el Palacio de San Cristóbal tendencias favorables a la fragmentación argentina, la opinión dominante en el gabinete de ministros era no alentar una guerra civil que pudiese arrastrar al Imperio a un lado o al otro y bloquear la navegación del Paraná (Doratioto 2008). Si Brasil se inclinó momentáneamente por la Confederación fue debido al recelo de Evangelista de Sousa, barón de Mauá desde 1854, por la "canalla de Buenos Aires" y a que Urquiza parecía la opción más segura para el pago de la enorme deuda argentina para con el Imperio (Doratioto 2008). Ahora bien, hacia 1859, ante la escalada bélica de la división argentina, el Imperio se rehusó a brindar mayores sumas al enclenque gobierno de Paraná, por lo que Urquiza se sintió disgustado y libre de acercarse al creciente poder militar paraguayo de la "dinastía" López.

Desaparecido Rosas, enemigo común del Paraguay y el Brasil, la mala delimitación del Mato Grosso meridional, zona poco poblada y rica en yerbatales, pasó a exacerbar el choque de aspiraciones territoriales entre el Imperio y el Paraguay (Moniz Bandeira 2006). Carlos Antonio López, presidente desde 1844, quería sacar a su país de su antiguo aislamiento y convertirlo en un actor relevante de la región, por lo que inició la primera fase de la modernización con la importación de armamento, manufacturas y maquinarias, así como la contratación de expertos extranjeros (Doratioto 2002). La financiación para todo ese desarrollo aparente era posible gracias a los empréstitos contraídos con la firma inglesa Blyth \& Co., las rentas de exportación de la yerba mate y la conexión comercial con Montevideo, única salida atlántica disponible para el estado paraguayo (Doratioto 2002). Dado que Paraguay contaba con los suelos más aptos para el cultivo de un producto que únicamente se consumía en el Río de la Plata, si López quería incrementar sus ingresos necesitaba ampliar las tierras dedicadas a su producción y hacer valer su peso en la región (Moniz Bandeira 2006). Ambicionando ocupar los yerbatales en la frontera con el Mato Grosso, López bloqueó sucesivamente la navegación del río Paraguay para forzar al Brasil a negociaciones limítrofes. Teniendo en cuenta los alineamientos políticos y los intereses económicos en el Río de la Plata, el presidente 
paraguayo buscaba a sus aliados naturales en el Partido Blanco uruguayo, hostil a la influencia brasileña en Uruguay, y en los federales del Litoral argentino, enemigos de la burguesía de Buenos Aires. En sentido inverso, la elite porteña tenía antiguas amistades en el Partido Colorado, formadas durante la guerra contra Rosas. En cuanto al Imperio, no le tembló el pulso para favorecer diplomáticamente los golpes de mano de los hombres del Partido Colorado en Uruguay, ni invadir el país para garantizar una salida ordenada de la crisis política. Tampoco temió hacer demostraciones de poder militar a López, cuando hizo falta. De este modo, las alianzas rioplatenses de la época rosista sobrevivieron y se tornaron más complejas, al incorporar a la trama de intereses al Imperio y al Paraguay, en un contexto de conflictividad debido a la guerra entre los dos estados argentinos, la intervención brasileña en Uruguay de 1854 y los altercados diplomáticos que casi llevaron al Paraguay y al Imperio a la guerra, entre 1854 y 1858.

La chispa que hizo explotar la frágil paz fue encendida, en 1861, por el presidente uruguayo Bernardo Berro. Como primer magistrado, Berro intentó defender los intereses nacionales contra la tutela económica y política que ejercía el Brasil en Uruguay, desde 1851. Esta no sólo se fundamentaba en los tratados asimétricos firmados por Andrés Lamas en 1851, sino también en el poder fáctico de los estancieros gaúchos en territorio oriental. Los brasileños residentes en Uruguay eran el 15\% de la población y ocupaban el $30 \%$ del territorio, en el que poseían las mejores estancias ganaderas en el norte del país (Lynch 1990). Junto a sus parientes en Río Grande do Sul, constituían un poderoso grupo de presión, que no dudaba en presionar al gobierno imperial para que interviniese en Uruguay, toda vez que sus intereses se veían en peligro (Lynch 1990). La preeminencia de la corporación de los estancieros gaúchos era tanto más molesta para Berro, ya que, como líder del Partido Blanco, representaba a los caudillos-estancieros de la campiña oriental que se veían perjudicados por los beneficios otorgados a sus competidores riograndenses. Además, los intercambios a través de la frontera no habían perdido su costado de bandidismo, desde que los señores gaúchos continuaban organizando sus californias en territorio oriental para el robo de ganado y capturar a los negros libres que se refugiaban en Uruguay (Grinberg 2019). Por todos estos motivos, tras rehusarse a renovar con Brasil los tratados de 1851, Berro eliminó todos los privilegios comerciales de los cuales gozaban los 
comerciantes brasileños en Montevideo y atacó los intereses de los estancieros gaúchos al imponer gravámenes al cruce de ganado por la frontera, crear nuevos impuestos a la propiedad y prohibir el uso de la mano de obra esclava en las haciendas en territorio oriental (Doratioto 2002). Sabiendo que los barones gaúchos inmediatamente demandarían auxilio militar en el Parlamento brasileño, Berro buscó apoyos en Urquiza y en Francisco Solano López, presidente paraguayo desde 1862, para equilibrar la esperada reacción brasileña y la oposición del Partido Colorado.

Las invitaciones de Berro a Urquiza molestaron particularmente a Bartolomé Mitre, presidente de la República Argentina unificada, amigo y deudor de ciertos personajes del Partido Colorado uruguayo (Doratioto 2002). La unidad de la Argentina aún era muy frágil y, si bien Urquiza se había retirado oficialmente de la política tras la derrota de Pavón, sólo se hallaba neutralizado, no borrado del mapa, por lo que el presidente porteño temía que los contactos con Berro tentasen al caudillo entrerriano a romper sus promesas y tratar de tomar el poder. De este modo, en septiembre de 1863, Mitre apoyó secretamente la "Cruzada Libertadora" del general colorado Venancio Flores contra el gobierno de Berro. Invadiendo territorio oriental desde la Argentina, Flores unió sus fuerzas con las milicias de los magnates gaúchos para derrocar al presidente uruguayo, desatándose una nueva guerra civil en la campiña oriental (Doratioto 2002). Si había algún personaje que no podía tolerar la interferencia argentina en Uruguay, era Francisco Solano López. Para 1863, el presidente paraguayo había heredado un estado sumamente militarizado, pero de base económica muy limitada y, siguiendo la política de su padre, entendía que debía mantener el vínculo político-comercial con Montevideo y negarse a ceder un palmo de tierra de los yerbatales al Brasil (Moniz Bandeira 2006). Suponiendo que la intervención de Flores era un golpe de mano argentino y brasileño guiado para alterar el equilibrio de poder en el Río de la Plata, López lanzó numerosas amenazas al Imperio y a Mitre, en defensa del gobierno blanco uruguayo, y trazó unos enlaces diplomáticos con Urquiza y Berro que perseguían la conformación de una confederación entre Paraguay, Uruguay, Entre Ríos y Corrientes (Moniz Bandeira 2006). La proyección de una unión entre los enemigos de Buenos Aires y Río de Janeiro, en la mirada de López, habría sido la garantía de la estabilidad regional y, a la vez, de la existencia de un espacio vital que hubiese permitido a Asunción incrementar las rentas 
de la economía agraria y convertirse en el centro político de la región (Moniz Bandeira 2006).

Con respecto al gobierno imperial, la guerra civil en Uruguay obligaba al gabinete dominado por los liberales de Zacarías de Goís e Vasconcelos a contentar a los siempre díscolos diputados riograndenses. Los daños alegados por los estancieros gaúchos exacerbaban a la prensa más nacionalista y llevaron a los diputados de Río Grande do Sul a exigir la intervención militar a toda escala en el Uruguay. Además, cabe la posibilidad de que el gobierno brasileño no quisiese dejar el control de la situación en manos de Flores, debido a su condición de general del Ejército Argentino y amigo de Mitre. Por otro lado, si, en 1852, Brasil había hecho la guerra a Buenos Aires por sus teóricas pretensiones de anexar la Banda Oriental, era de esperarse una reacción similar ante las aspiraciones de López de unir a las "provincias del Paraná" bajo su propio liderazgo. Como fuese, ignorando los ultimátum de López, en noviembre de 1864, el gabinete de San Cristóbal permitió al Ejército Imperial invadir el territorio oriental para reprimir a las fuerzas del gobierno blanco y tomar Montevideo. Creyendo que la suerte ya estaba echada, López respondió con la captura del buque brasileño Marquês de Olinda y el ataque sobre el Mato Grosso. Días después, las fuerzas brasileñas lograban la rendición de Montevideo y colocaban a Flores en el poder. Queriendo llevar la guerra a territorio brasileño, López solicitó permiso a Mitre para penetrar en territorio argentino. Ante la negativa del presidente, el mariscal ordenó a sus comandantes invadir la provincia de Corrientes el 13 de abril de 1865, violando la neutralidad declarada por el gobierno de Buenos Aires.

El ataque paraguayo en territorio argentino dio a Mitre la excusa que necesitaba para justificar, en el frente interno argentino, la alianza con Brasil. El 1 de mayo fue firmado en Buenos Aires el tratado que declaraba la alianza ofensiva-defensiva entre la Argentina, el Brasil y el Uruguay contra Paraguay. Los aliados se comprometían a no firmar la paz por separado y a no cejar el esfuerzo bélico hasta tanto no haber destruido al gobierno paraguayo. Con todo, los artículos del tratado que afirmaban la independencia y la soberanía territorial del Paraguay provocaron algunos resquemores entre los firmantes. Mitre y su canciller Rufino Elizalde se resistían a aceptar dichas condiciones, ya que aspiraban a incorporar al país enemigo a la unión de provincias argentinas o, en todo caso, a anexionar el 
disputado Gran Chaco. Si la integridad territorial del Paraguay fue finalmente incluida fue gracias a la firmeza del negociador brasileño, Francisco Octaviano de Almeida Rosa. Siguiendo los tradicionales argumentos de Paulino Soares de Souza, el ministro comprendía que la independencia del Paraguay (y del Uruguay) era un factor fundamental para la hegemonía brasileña en el Río de la Plata. Sin embargo, para obtener el asentimiento de Mitre, Almeida Rosa debió ceder a una parte de las pretensiones territoriales argentinas. Elizalde insistió para que Brasil reconociera la soberanía argentina sobre el Chaco Boreal, es decir, sobre toda la margen derecha del río Paraguay, hasta la Bahía Negra, y sobre las antiguas Misiones en la orilla izquierda del río Paraná, hasta el río Iguazú. El brasileño aceptó y a cambio logró el reconocimiento argentino de la soberanía paraguaya y de las demandas territoriales brasileñas en la frontera, estableciendo el límite en la línea entre los ríos Apa e Igurey. De esta manera, Brasil se hacía con todas las tierras en disputa con la Paraguay, cumpliendo sus aspiraciones territoriales de acuerdo con el uti possidetis y eliminando la competencia paraguaya en la producción y comercialización de la yerba mate (Moniz Bandeira 2006).

Las noticias del tratado fueron recibidas con mucha frialdad en Río de Janeiro. Para los conservadores, Almeida Rosa se había excedido en las concesiones hechas a los argentinos. Muchos veían con intranquilidad la idea de una frontera tan extensa con la Argentina, la cual, en caso de conflicto, podría bloquear la comunicación fluvial al Mato Grosso y atacar al Imperio en su flanco más débil. De hecho, el marqués de São Vicente recurrió a las siempre alarmantes tesis sobre la reconstrucción del virreinato del Río de la Plata, mientras que el vizconde de Jequitinhonha recordó a sus colegas que el verdadero y permanente enemigo del Brasil era el gobierno de Buenos Aires (Nabuco 1897). Según esta lógica, el Imperio debía considerar la Alianza como un mero pacto militar transitorio, cuyas disposiciones relativas a los límites eran indicativas y ajustables, por lo que podrían ser alteradas una vez alcanzada la victoria. Incluso el liberal José Antônio Saraiva, ministro de Relaciones Exteriores, declaró que la cesión completa del Chaco y las Misiones implicaba la creación de una tenaza argentina alrededor de la reducida república guaraní, que permitiría a los argentinos anexarla una vez fuese derrotada (Doratioto 2002). Saraiva sostenía que la Argentina no debería obtener ni un palmo de tierra al norte 
del río Pilcomayo y que, en el caso de que los porteños no aceptasen reducir lo pactado, Brasil debería exigir que se incrementasen sus propias ganancias territoriales, ya que obtenía mucho menos que su histórico rival (Doratioto 2002). Admirador del republicanismo argentino, Almeida Rosa contestaba que la cooperación con las otras naciones era un hecho positivo y que, debido a las tradiciones diplomáticas imperiales, Brasil no podía contar con el apoyo de ninguna (Doratioto 2002). En cuanto al tema del Chaco, el diplomático consideraba que su cesión era precio menor, si se tenía en cuenta que con ello Mitre había aceptado respetar la independencia paraguaya y había reconocido las adquisiciones territoriales del Imperio (Doratioto 2002).

Para paliar el aislamiento internacional brasileño, el ministerio de Relaciones Exteriores había puesto en movimiento a la experimentada red diplomática imperial con el objetivo de articular unas relaciones internacionales favorables y atajar posibles amenazas desde el extranjero (Moniz Bandeira 2006). En primer lugar, a través de sus contactos portugueses y las relaciones familiares de Pedro II, el Palacio de Itamaraty logró restablecer las relaciones oficiales con Gran Bretaña, cortadas desde 1863 a raíz del affaire Christie. Al mismo tiempo, el Imperio habilitó la libre navegación internacional de la cuenca del Amazonas, para así apaciguar a las repúblicas del Pacífico y los históricos reclamos librecambistas de Gran Bretaña, Francia y los Estados Unidos (Moniz Bandeira 2006). Por otro lado, el Imperio se propuso difundir en Europa la imagen de una Triple Alianza abanderada de la civilización, que luchaba contra la barbarie y la tiranía de López. A diferencia de Paraguay, país poco conocido y calumniado desde hacía años por su régimen autoritario, Brasil contaba en el Viejo Mundo con una fama de Imperio estable y constitucional (Johansson 2017). Además, los fluidos intercambios comerciales, las relaciones con la aristocracia europea y los vínculos intelectuales con letrados portugueses colaboraron con el equipo diplomático brasileño (Johansson 2017). De esta manera, Brasil logró neutralizar los vanos intentos paraguayos por obtener apoyos materiales o financieros, así como las tentativas de las repúblicas andinas y Estados Unidos por mediar a favor del gobierno de Asunción (Moniz Bandeira 2006).

En cuanto a la opinión pública brasileña, luego de las primeras reacciones exaltadas de patriotismo, hacia 1866 aparecieron las primeras 
respuestas adversas, provocadas por la lentitud de la ofensiva aliada, la derrota de Curupayti y las diferencias entre los oficiales brasileños y argentinos. El optimismo respecto al andar del conflicto fue recuperado recién a principios de 1868, gracias a las aplastantes victorias del marqués de Caxias en suelo paraguayo (Silveira 2015). Con el tiempo, el reclutamiento masivo y las evocaciones al espíritu nacional en la prensa y en las manifestaciones públicas lograron que sectores cada vez más amplios de la sociedad adquirieran una idea de pertenencia a una comunidad mayor que sus propios universos locales (Johansson 2017). Hasta la Guerra del Paraguay, la penetración ideológica del Imperio solamente había creado sentimientos de identidad nacional entre las elites que se beneficiaban del sistema esclavista y oligárquico. Fue precisamente la experiencia colectiva de una guerra de seis años lo que movilizó a la nación entera, ya que obligó a soldados de distintas regiones y diversos grupos étnicos a compartir vivencias e introdujo la liturgia nacionalista en todos los escalafones de la educación, la prensa y la vida pública (Carvalho 2003).

\section{El fin de la Conciliação}

Desde 1853, la Conciliação entre liberales y conservadores había morigerado las contradicciones internas del país para incorporar a los notables provinciales a la conducción del Imperio, favoreciendo una ideología nacional propia. Ahora bien, con el tiempo, la modernización del país, impulsada por la capitalización de las actividades agropecuarias, creó unas condiciones sociales que contrastaban con el "liberalismo estamental" de la conciliación y no correspondía con los valores jerárquicos de la monarquía brasileña (Alonso 2009). Para fines de la década de 1860, el cuadrilátero del centro-sur, formado por las provincias de Minas Gerais, Río de Janeiro, San Pablo y Rio Grande do Sul, ya desplazaba a las provincias azucareras del nordeste como zona vital del Imperio y producía un importante trasvase de población y capitales. Especialmente San Pablo, la región más tardíamente explotada por los hacendados cafetaleros, experimentó un impresionante proceso de crecimiento económico y el empoderamiento de una ambiciosa burguesía. Inspirados por el positivismo europeo, los liberales del centro-sur sostenían que se debía abrir el país para 
atraer inmigrantes y para modernizar su aparato productivo, mediante novedades como el ferrocarril y la importación de capitales extranjeros ( Da Costa 1986). Además, adherían a un ideario político reformista con aras de sanear la paternalista democracia brasileña, reducir la injerencia del Estado central, garantizar las libertades individuales y confiar en el progreso por medio de la ciencia (Da Costa 1986). Particularmente, la elite paulista se resentía de la asimetría entre su poder económico y la escasa relevancia que ejercía en los escalafones superiores del Estado. De ahí su reclamo por recuperar las autonomías locales, descentralizando el poder y separando la justicia de la autoridad monárquica. El descontento incluso pasaba por figuras ascendientes en Río de Janeiro, que veían como el sistema político era controlado por los grandes propietarios esclavistas y dificultaba el ingreso de nuevos hombres al Senado, el gabinete o el Consejo de Estado (Da Costa 1986).

Para 1864, ciertos espíritus liberales de la Conciliação fundaron la Liga Progressista con ánimos de proponer en el Parlamento un programa de leyes ilustradas, entre las cuales se hallaba la descentralización administrativa, la reforma electoral y un nuevo Código Civil. Con todo, la inercia de la conciliación liberal-conservadora logró que el moderado programa reformista de la Liga no produjera inmediatamente la ruptura ideológica que se podía esperar. Además, el estallido de la Guerra del Paraguay, inicialmente, produjo un apoyo considerable a la causa del Imperio entre el grueso de los liberales. Fue apenas en 1866, cuando la mala conducción de la guerra por parte del gabinete presidido por el liberal Zacarías exacerbó los disensos partidarios. Luego de las victorias militares de Caxias, sus correligionarios del Partido Conservador se sintieron fuertes para conspirar contra el gobierno. Arrastrado por el faccionalismo de la Corte, Pedro II utilizó sus poderes constitucionales para deshacer la Cámara de Diputados, convocar a elecciones y otorgar el gabinete de ministros a los conservadores. Inevitablemente, la crisis ministerial quebró la Conciliação, provocando, además la escisión interna de ambos partidos de la Corte (Alonso 2009). Si muchos conservadores se pasaron a la bancada liberal, los que se mantuvieron en el partido monárquico por excelencia quedaron informalmente divididos en intransigentes y moderados. Análogamente, dentro del liberalismo histórico surgieron facciones de radicales 
republicanos de ideas más jacobinas que las del moderado reformismo de los liberales tradicionales.

Los grupos moderados conservadores y liberales compartían su creencia en la separación entre elites y pueblo, ya que desconfiaban de las virtudes de las masas para gobernarse democráticamente. Las dos facciones de moderados temían que una ampliación repentina y no controlada de los derechos políticos hiciese peligrar la estabilidad del orden social y el liderazgo de las clases superiores, las cuales debían adaptarse a las nuevas condiciones y aceptar la inevitabilidad de ciertas transformaciones (Alonso 2009). En cuanto a la situación del Imperio en un continente de repúblicas, los liberales no renegaban de la hegemonía continental brasileña, pero sí de los métodos intervencionistas de la política exterior tradicional del Segundo Reinado. Mientras que los conservadores habían visto siempre la realidad democrática de los países vecinos como una amenaza, la visión liberal tenía en la cooperación y la solidaridad entre naciones una oportunidad para terminar con la enemistad secular con los pueblos del Río de la Plata y poder dedicar las energías del Imperio a su modernización interna (Alonso 2009). De todos modos, esta descripción general debería ser matizada y complejizada. En muchos casos, las iniciativas políticas también estaban altamente influenciadas por los intereses provinciales, tanto como por las preferencias ideológicas.

Otro elemento de cohesión entre conservadores y liberales había sido la esclavitud. Entendida como el fundamento del sistema económico y del orden social del Imperio, ambos grupos la habían defendido frente a las presiones británicas. De hecho, desde 1850, comenzaba a vislumbrarse en Brasil lo que Ricardo Salles llama una "sociedad esclavista madura" (Salles 2013). Según este autor, desde que carecieron de la reserva inagotable de africanos que provenía del tráfico, los patrones comenzaron a garantizar cierta mejoría en las condiciones de vida de sus esclavos, lo cual favoreció el crecimiento vegetativo de la población de color y su visibilidad en la sociedad (Salles 2013). Además, si los brasileños nunca habían sido totalmente ajenos a las manumisiones, a partir de 1850, éstas se multiplicaron, particularmente en el nordeste, ya que, a medida que el eje económico del Imperio se corría hacia el centro-sur, las plantaciones azucareras perdían dinamismo y se hacía imposible para los senhores de engenho mantener con buena salud a sus familias de esclavos. De este modo, 
hubo un aumento significativo de la población de libertos negros y mulatos que se convirtió en mano de obra libre en las ciudades y haciendas del centro-sur y que, gracias a la heterogeneidad racial del Brasil, se integraron fácilmente en los segmentos bajos de la sociedad (Salles 2013) La tendencia era congruente con la historia social brasileña, ya que, a diferencia de la separación abismal entre población blanca y negra del Deep South estadounidense, desde la época portuguesa, el mestizaje y el blanqueamiento habían moderado en cierta medida la marginación de la población de color del Brasil (Salles 2013). Finalmente, para la época de la Guerra del Paraguay, el reclutamiento de miles de negros para formar el Ejército Imperial y el discurso civilizatorio antiparaguayo no hicieron más que resaltar las contradicciones propias y reforzar a aquellas voces que reclamaban la extinción definitiva de la esclavitud (Besouchet 1994). Aunque las inclinaciones liberales de Pedro II lo inducían a querer abolir la esclavitud, otros ministros y senadores más prudentes sabían que liberar de un solo golpe a todos los esclavos del Imperio sería sumamente perjudicial para la economía nacional y la paz social (Besouchet 1994).

Finalizada la guerra y ante las demandas de reformas liberales, en 1871, el emperador nombró como presidente del gabinete de ministros a José da Silva Paranhos, vizconde de Rio Branco, estadista e intelectual de tendencia reformista dentro del Partido Conservador, cuya juvenil filiación liberal y sus vínculos masónicos le permitían moverse con ductilidad entre los moderados de los dos grandes partidos (Besouchet 1994). Entendiendo que era mejor dar algo a las demandas del progresismo, el nuevo presidente del gabinete hizo pasar una serie de resoluciones en el Parlamento, como la ley de Libertad de Vientres y las reformas de la Guardia Nacional, de las cortes y el sistema de conscripción, así como promovió la expansión del sistema ferroviario y la inmigración. Sus medidas, agradables a las facciones liberales, no alteraron en profundidad el predominio del partido monárquico, pero profundizaron la división en el seno del conservadurismo entre emperrados y reformistas (Barman 1999). Al mismo tiempo, un segundo dilema profundizó los clivajes entre conservadores y liberales: el conflicto con la Iglesia. Desde la independencia, los ministros de la corta Braganza habían cuidado la unión simbiótica entre el Estado y la Iglesia, ya que veían en ella institución clave para la legitimidad del orden social estamental y el respeto de la Corona (Souza 2013). Heredero del despotismo 
ilustrado pombalino, el Estado brasileño ejerció un patronato moderado sobre la Iglesia y supo encontrar un término medio en sus relaciones con los obispos (Besouchet 1994). El equilibrio pactado comenzó a peligrar cuando las revoluciones de 1848 provocaron la reacción conservadora de Pio IX, quien acentuó el celo de la Iglesia por sus viejas prerrogativas, al mismo tiempo que la unificación italiana dividía a la opinión pública y abría una grieta entre las clases dirigentes (Halperín Donghi 2005). Como en otras zonas del mundo católico, la tendencia ultramontana derramó sobre los obispos locales, los cuales, sin autorización imperial, en marzo de 1872, decidieron aplicar la bula de papal que excomulgaba a los masones de las actividades de la Iglesia. De este modo, la determinación de los sectores más reaccionarios del catolicismo brasileño exacerbó el anticlericalismo de los liberales y provocó un serio problema en el seno de un Estado monárquico que se había visto siempre como patrono y aliado de la Iglesia (Da Costa 1986). La cuestión religiosa fracturó el campo político independientemente de las afiliaciones partidarias y, curiosamente, atrajo el apoyo de los liberales más radicales al gobierno imperial. De este modo, Rio Branco pudo mantener un frágil equilibrio de fuerzas en el frente interno, en momentos en que las relaciones diplomáticas con los argentinos se tornaban tensas, debido a los desacuerdos relacionados con el reparto del territorio paraguayo y la definición de límites (Graham 1990).

\section{La cuestión de las fronteras argentinas}

El gobierno del vizconde de Rio Branco (1871-1875) se podría caracterizar como un período transicional entre el sólido Imperio de los gobiernos de la Conciliação y la época de fracturas internas que llevaron a la extinción de la monarquía. En términos de política exterior, la cuestión del Plata, acerca de la definición de las fronteras argentinas, volvió a tomar protagonismo en la agenda del Palacio de Itamaraty y, entre 1872 y 1875, cancilleres, diplomáticos y escritores argentinos y brasileños rozaron la posibilidad de un nuevo enfrentamiento armado. Si bien pertenecía a la facción más moderada del conservadurismo brasileño, Rio Branco apoyaba públicamente la política exterior trazada por Paulino Soares de Souza en 1851, basada en el uti possidetis, la hegemonía en el Plata y la tradición 
monárquica (Doratioto 2016). El vizconde era un realista. Creía en las ventajas de la paz, pero sostenía que el adagio latino si vis pacem, para bellum ("si quieres la paz, prepárate para la guerra") era una máxima de seguridad nacional (Doratioto 2016). Esta doctrina se justificaba especialmente en el hecho que los estadistas brasileños nunca habían dejado de preocuparse por las veleidades de los porteños en reconstruir el viejo espacio virreinal. Incluso un liberal de la talla de Joaquim Nabuco escribiría, en 1875, que la historia de relaciones argentinas con sus repúblicas hermanas demostraba

[...] la esperanza de rehacer algún día dentro de los límites de la cuenca del Plata, ya que no en totalidad, el antiguo virreinato. Aún sueñan con los Estados Unidos de la América del Sur muchos hijos de Buenos Aires, en quienes la tradición de un pasado y una literatura comunes, pesan todavía con la misma fuerza que sobre la generación de mediados de siglo, contemporánea del sitio de Montevideo. (Nabuco 1901, 11-12)

Desde la perspectiva brasileña, la reconstrucción del virreinato del Río de la Plata o los Estados Unidos del Sur equivalía a la aparición de un temido estado rioplatense con una extensión territorial que amenazaría la integridad del Imperio y su primacía regional. Fiel a esta escuela de pensamiento, Rio Branco estaba convencido de que, tras la victoria en Paraguay, Brasil debía acercarse al enemigo derrotado e impedir la expansión territorial argentina, acordada en el Tratado de 1865. Concretamente, no era descabellado imaginar que, si permitía a los argentinos adueñarse del Chaco Boreal, éstos podrían bloquear las comunicaciones del Mato Grosso y utilizar sus bases chaqueñas para desestabilizar la situación política paraguaya $\mathrm{y}$ eventualmente absorber a todo el país (Nabuco 1901). El Imperio no había peleado una guerra de seis años para intercambiar un enemigo expansionista por otro. En todo caso, como aventuraba Nabuco en sus escritos, las sospechas brasileñas sobre el "imperialismo argentino" se veían un tanto fundadas debido a las actitudes de los propios dirigentes de Buenos Aires (Nabuco 1901). Con todas sus diferencias, Rosas y Mitre habían sido dos porteños que se habían resistido a reconocer la independencia paraguaya y que habían financiado y apoyado sendas intervenciones armadas en la Banda Oriental. Además, en 1864, Edward Thornton, ministro británico en 
Buenos Aires, supo de Mitre que éste no descartaba incorporar al Paraguay a la Argentina, si las condiciones de la posguerra lo permitían. Incluso Rufino de Elizalde le confesó al inglés sus sueños de ver reintegradas en el tronco de la nación argentina, en el futuro cercano, a ambas repúblicas del Paraguay y Bolivia (Doratioto 2002). Por si fuera poco, desde 1868, el presidente argentino era Domingo Faustino Sarmiento, cuyas antipatías por la monarquía esclavista y sus ideas respecto a la unión de los estados del Plata eran perfectamente conocidas. En Argirópolis, obra de 1850, el sanjuanino había escrito que "Los Estados del Plata están llamados, por los vínculos con que la naturaleza los ha estrechado entre sí, a formar una sola nación", para defenderse en mejores términos del verdadero enemigo que era el Brasil (Sarmiento 2016, 54).

La predisposición de Sarmiento hacia el Brasil se diferenciaba diametralmente a la de su predecesor en la presidencia. Hallando en los liberales del gabinete imperial de 1864 unos espíritus afines, Mitre había creído encontrar en el Imperio un aliado confiable para terminar con la desestabilidad producida por los caudillos revoltosos, como el propio López (Alonso Piñeiro 1972). En cambio, Sarmiento hizo todo lo posible por desligarse de la Alianza y se empantanó en una política exterior contradictoria, que le impidió a la Argentina concretar los que habían sido sus objetivos de expandirse en el Chaco Boreal y de tutelar la salida democrática paraguaya. En primer término, buscando limitar la influencia del Brasil en Paraguay, en 1869, el canciller Mariano Varela dinamitó las ganancias territoriales argentinas estipuladas en el tratado, al argumentar que Paraguay era un Estado soberano que no podía ser mutilado y que "la victoria no da derechos a las naciones aliadas para declarar por sí, límites suyos los que el tratado señaló" (Nabuco 1897, 279). Tras la constatación de que dicha postura solo permitía al Imperio acrecentar su semiprotectorado paraguayo, Sarmiento nombró canciller a Carlos Tejedor, en 1870, el cual durante cinco años adoptó una pose demandante ante el Palacio de Itamaraty, con el objetivo de obtener el reconocimiento brasileño a los derechos argentinos en el Chaco Boreal. Luego de que, en enero de 1872, Brasil y Paraguay firmasen bilateralmente unos tratados de límites, comercio y amistad que dejaban afuera a la Argentina del reparto del botín de guerra, la poca moderación de Tejedor exacerbó las posturas belicistas en ambos países y limitó las perspectivas de arreglo de las misiones 
diplomáticas encargadas a Mitre, en 1872 y 1873. Para 1875, el propio Tejedor se encargó personalmente de las negociaciones en Río de Janeiro, donde se ganó el encono de los brasileños por sus maquinaciones inefectivas con el enviado paraguayo y su desprecio por los protocolos de la Corte imperial. Finalmente, tras el bloqueo de Rio Branco a todas las iniciativas diplomáticas argentinas para expandirse sobre el norte chaqueño, el tratado definitivo de paz y límites entre la Argentina y el Paraguay fue firmado en 1876, por Bernardo de Irigoyen y Facundo Machaín, bajo vigilancia brasileña. El límite internacional entre ambos países quedaba dibujado en el río Pilcomayo y el resto del Chaco Boreal se dividía en dos secciones: la superior era reconocida automáticamente bajo soberanía paraguaya y la inferior quedaría sometida al arbitraje del presidente de los Estados Unidos, quien dos años después dictaminó su laudo a favor del Paraguay.

De esta manera se gestó el final formal del vínculo estratégico argentinobrasileño. Si dicha Alianza, formada por grupos minoritarios en cada país al calor de la agresión de Francisco Solano López, había empezado a tambalear desde el momento en que el enemigo común era derrotado en 1868, los objetivos antagónicos de cada aliado en el vencido Paraguay hicieron el resto para retrotraerlos a su antigua relación de rivalidad (Doratioto 1999). Siguiendo la tradicional política exterior del vizconde del Uruguai, Rio Branco dio muestras de verdadera realpolitik, sin dejar de pensar en el prestigio del Imperio como factor de poder en el continente, logrando colocar al Paraguay bajo la sombra del Brasil y desbaratando todas las tentativas de la Argentina para aumentar su territorio nacional y controlar la situación política paraguaya. Con todo, sus éxitos en términos de política exterior no impidieron que una serie de problemas de política interna y dificultades económicas estimularan, para mediados de 1875, la desestabilización de su gabinete. En primer lugar, la prolongación de la Revolta do Quebra-Quilos (1872-1877) en el nordeste, el conflicto con la Iglesia y el bloqueo en la Cámara baja a la ley de reforma electoral minaron la credibilidad del gobierno y su capacidad de llegar a consensos viables (Barman 1999). Por otro lado, la reputación de Rio Branco fue duramente atacada cuando salió en rescate financiero del Banco Mauá, institución asociada al Estado imperial desde la década de 1850. Los problemas del banco formaban parte de la Gran Depresión Brasileña de 1875, crisis económica que también mermó el capital político del gobierno y que había 
sido provocada por una caída en los precios mundiales del café. Al mismo tiempo, la amnistía dada por Pedro II a los obispos ultramontanos también contribuyó a la renuncia de Rio Branco (Da Costa 1986). En definitiva, la conjunción de desarrollos políticos y económicos desfavorables, sumados al desgaste propio de cuatro años de gobierno, llevó a Paranhos a solicitar su renuncia al emperador en junio de 1875. A partir de entonces, asegurado el frente externo en el Río de la Plata, fue el frente interno el mayor factor de descomposición para el Imperio, en el cual la escalada del descontento del Ejército, los problemas con la Iglesia, las demandas de reformas de Estado profundas y las campañas abolicionistas erosionaron lentamente los fundamentos de la monarquía y produjeron, en 1889, la definitiva abdicación de la casa de Braganza de su Imperio sudamericano.

\section{Consideraciones finales}

La Cuestión del Plata ha sido una constante en la breve historia del Imperio del Brasil. Herencia de los conflictos luso-españoles del siglo XVIII, la conflictividad en la cuenca del Río de la Plata produjo, desde 1817 y hasta 1876, distintas formas de intervención de parte del Brasil y de sus magnates de frontera. La anexión directa de la Banda Oriental, la secesión de la República de Río Grande, la campaña contra Rosas y Oribe, las represalias contra los blancos uruguayos, la guerra y la ocupación del Paraguay han sido capítulos distintos de un mismo conflicto, causado por la inestabilidad de las provincias rioplatenses, las pretensiones gaúchas y las aspiraciones brasileñas de ejercer la hegemonía o el control en la región. Con todo, la capacidad del Imperio de intervenir en los asuntos vecinos estuvo siempre condicionada por su propia unidad interna y las limitaciones que impuso la era de las revueltas regionales y el momentáneo sistema federal, entre 1831 y 1840 . Reestablecida la autoridad central con la mayoría de Pedro II, los ministros del Imperio buscaron continuar el legado portugués de intervención en el Río de la Plata y crear un sistema de relaciones en el que el Brasil fuese el árbitro de las disputas regionales. En términos ideológicos, la esclavitud, el uti possidetis, la grandeza imperial y los valores tradicionales de la monarquía fueron la argamasa de valores que sostuvieron la unidad de los miembros de las elites regionales del Brasil, en 
torno a la Corona y frente a las percepciones de amenazas externas. Entre éstas, la supuesta política expansiva de Buenos Aires no era la menor. Fue el vizconde de Uruguai, quien ideó el sistema de alianzas que derrotó a Rosas, en 1852, estableciendo como prioridad de política exterior el objetivo de impedir cualquier tipo de agrupamiento de las repúblicas platinas bajo una misma autoridad. Desde la perspectiva brasileña, las posturas de Rosas, Mitre y Sarmiento frente a las repúblicas del Uruguay y el Paraguay daban la impresión a los estadistas del Imperio de que los argentinos buscaban reconstruir la territorialidad del viejo virreinato del Río de la Plata. Un estado de tales características hubiese sido un competidor directo para el hegemón regional que pretendía ser el Brasil, no sólo por sus recursos humanos y materiales, sino porque hubiese sido capaz de bloquear la navegación de los ríos interiores, tan necesaria para las comunicaciones mediterráneas del Imperio, al mismo tiempo que hubiese hecho de fuerza de atracción republicana para los díscolos señores de Río Grande do Sul.

Precisamente, los magnates gaúchos fueron un factor de poder considerable en la política interna y externa del Imperio, desde el fin de la guerra de los farrapos, en 1845. La estructura social de su provincia los acercaba más a los caudillos rioplatenses que a los aristócratas del azúcar y su proyecto político-económico divergía, en muchos aspectos, de las perspectivas centralistas y estamentales de la monarquía brasileña. Con poderosos intereses en la campiña uruguaya y el puerto de Montevideo, los gaúchos fueron los principales abanderados de la guerra en el Parlamento brasileño, en 1851 y en 1864. El período entre éstos años fue precisamente el momento de más claro dominio del Brasil en el Río de la Plata, la era de la Conciliação entre liberales y conservadores. Significativamente, a pesar de sus divergencias en torno a la esclavitud, el sistema electoral y el grado de centralización, ambas corrientes no debatieron acerca del dominio que el Imperio debía ejercer sobre sus vecinos republicanos del sur, ni sobre la misión permanente de evitar cualquier forma de predominio argentino sobre las repúblicas vecinas del Plata. A estos motivos realistas y continuos de la política de Itamaraty se debió el chispazo que provocó la Guerra de la Triple Alianza. El conflicto demostró que el Imperio no sólo estaba preparado para combatir a porteños expansivos, como Rosas, sino también a todo aquel caudillo rioplatense que buscase construir un poder alternativo en la región y hostil al Imperio, como el mariscal López. Derrotado el tirano, el Imperio 
volvió a reactivar la enemistad con Argentina, país que pretendía hacer valer sus derechos al Gran Chaco y las Misiones, estipulados en el Tratado de 1865. La política exterior de Itamaraty era implacable y coherente con los objetivos trazados por el vizconde de Uruguai en 1849: impedir la construcción de la Gran Argentina, los Estados Unidos del Sur o el virreinato del Río de la Plata, llamase como se llamase el proyecto de expansión porteño. Se trataba de evitar la unión de las repúblicas platinas, garantizar la libre navegación de los ríos, cuidar la integridad territorial brasileña y mantener la hegemonía imperial.

En conclusión, la superioridad regional del Brasil respecto de la Argentina, durante el Segundo Reinado, no estuvo solo basada en sus vastos recursos humanos y materiales, sino en el hecho de que pudo sostener una política exterior realista que gozaba de plena legitimidad entre las dirigencias y la intelectualidad del Imperio al formar parte del acervo de tradiciones políticas de la monarquía de los Braganza. Fue Brasil, sus militares, sus banqueros y sus diplomáticos, quienes actuaron en consonancia para cuidar el equilibrio de poder regional, lograr las victorias armadas en 1852, 1864 y 1870, y conducir el restablecimiento del orden y las instituciones en los países derrotados de Uruguay y Paraguay. Hacia 1875, mediante el ejercicio de una presión constante y coherente en el Río de la Plata desde el final de la guerra, el gabinete de Rio Branco logró mantener al Paraguay bajo su órbita, forzar los acontecimientos a su favor y anular todas las tentativas argentinas de modificar un status quo regional que garantizaba la hegemonía del Brasil y su influencia en los asuntos internos de los estados platinos. Tras seis años de conflicto diplomático, a pesar de la renuncia de Rio Branco a la presidencia del consejo de ministros, los tratados Irigoyen-Machaín fueron un verdadero triunfo que consagró formalmente lo que Brasil había conseguido por la fuerza de los hechos consumados.

\section{Referencias}

Alonso Piñeiro, Armando. 1972. La misión diplomática de Mitre en Río de Janeiro - 1872. Buenos Aires: Instituto Mitre. 
Alonso, Angela. 2009. “Apropriação de idéias no Segundo Reinado". En $O$ Brasil Império, editado por K. Grinberg y R. Salles, págs. 1-30. Río de Janeiro: Civilização Brasileira.

Barman, Roderick. 1999. Citizen Emperor: Pedro II and the Making of Brasil, 1825-1891. Stanford: Stanford University Press.

Barrio, César de Oliveira Lima. 2018. O Império do Brasil e a politica de intervenção no Rio da Prata (1843-1865). Brasilia: Fundação Getulio Vargas.

Besouchet, Lídia. 1994. José María da Silva Paranhos, vizconde do Rio Branco. Ensayo histórico-biográfico. Buenos Aires: Viau.

Bethell, Leslie. 1985. "The Independence of Brazil". En The Cambridge History of Latin America, editado por L. Bethell, págs. 157-196. Cambridge: Cambridge University Press.

—. 1990. "Brasil (1822-1850)". En Historia de América Latina, editado por L. Bethell, págs. 319-377. Barcelona: Crítica.

1996. The Paraguayan War (1864-1870). Londres: Institute of Latin American Studies.

Carvalho, José Murilo de. 2003. "Brasil. Naciones imaginadas". En Inventando la nación. Iberoamérica. Siglo XIX, editado por F. Guerra y A. Annino, págs. 501-532. Ciudad de México: Fondo de Cultura Económica.

Cervo, Amado Luiz y Bueno, Clodoaldo. 2015. História da política exterior do Brasil, $4^{\mathrm{a}}$ ed. Brasilia: Editora UnB.

Corrêa, Luis Felipe de Seixas. 2016. "Honório Hermeto Carneiro Leão, the Marquis of Paraná: diplomacy and power in the Plata". En Brazilian Diplomatic Thought. Policymakers and Agents of Foreign Policy (17501964), págs. 237-276. Brasilia: Fundação Alexandre de Gusmão.

Da Costa, Emilia Viotti. 1986. "Brazil: The Age of Reform, 1870-1889". En The Cambridge History of Latin America, editado por L. Bethell, págs. 725-777. Cambridge: Cambridge University Press.

Doratioto, Francisco. 1999. "De aliados a rivais: o fracasso da primeira cooperação entre Brasil e Argentina". Revista Multipla IV (6): 21-39. 2002. Maldita guerra. Nova história da Guerra do Paraguai, $2^{\mathrm{a}}$ ed. Brasilia: Companhia das Letras. 2008. “O Império do Brasil e a Argentina (1822-1889)". Textos de História 16 (2): 217-247. 
2016. "The Viscount of Rio Branco: sovereignty, diplomacy and power". En Brazilian Diplomatic Thought. Policymakers and Agents of Foreign Policy (1750-1964), editado por J. V. d. S. Pimentel, págs. 275316. Brasilia: Fundação Alexandre de Gusmão.

Ferreira, Gabriela Nunes. 2006. O Rio da Prata e a Consolidação do Estado Imperial. São Paulo: Hucitec.

2016. "Paulino José Soares de Souza, the Viscount of Uruguay: building the instruments of Brazilian diplomacy". En Brazilian Diplomatic Thought. Policymakers and Agents of Foreign Policy (17501964), editado por J. V. d. S. Pimentel, págs. 126-166. Brasilia: Fundação Alexandre de Gusmão.

Goes Filho, Synesio Sampaio. 2013. As fronteiras do Brasil. Brasilia: Fundação Alexandre de Gusmão.

Graham, Richard., 1990. "Brasil (1850-1870)". En Historia de América Latina, editado por L. Bethell, págs. 378-418. Barcelona: Crítica.

—. 2003. "Formando una nación en el Brasil del siglo XIX". En Inventando la nación. Iberoamérica. Siglo XIX, págs. 629-653. Ciudad de México: Fondo de Cultura Económica.

Grinberg, Keila. 2019. "Emancipación y guerra en el Río de la Plata, 18401865: hacia una historia social de las relaciones internacionales". Historia mexicana 69 (2): 693-742.

Guazzelli, César Augusto. 2015. "La República Rio-Grandense y el retorno de la "Pátria Grande" (1838-1843)". Pasado Abierto 2: 153-196.

Guimarães, Manoel Luis Salgado. 1988. "Nação e Civilização nos Trópicos: o Instituto Histórico e Geográfico Brasileiro e o Projeto de uma História Nacional". Revista de Estudos Históricos 1: 5-27.

Halperín Donghi, Tulio. 2005. Historia contemporánea de América Latina $19^{a}$ ed. Madrid: Alianza.

Jardim, Wagner Cardoso. 2011. "A Geopolitica no Tratado da Triplice Aliança: Brasil/ Argentina / Uruguai”. Anais do XXVI Simpósio Nacional de História: 1-14.

Johansson, María Lucrecia. 2017. La gran máquina de publicidad. Redes transnacionales e intercambios periodísticos durante la guerra de la Triple Alianza (1864-1870). Sevilla: Universidad Internacional de Andalucía. 
Lynch, John. 1990. "Las repúblicas del Río de la Plata”. En Historia de América Latina, editado por L. Bethell, págs. 264-315. Barcelona: Crítica.

Marchena Fernández, José. 2015. "Del Tajo al Amazonas y al Plata: las repercusiones atlánticas de las guerras entre las Coronas española y portuguesa en la Edad Moderna (1640-1777)". En Hombres, poder y conflicto: estudios sobre la frontera sudamericana y su crisis, págs. 12116. La Plata: UNLP.

Mattos, Ilmar Rohloff de. 2003. "La experiencia del Imperio del Brasil". En Inventando la nación. Iberoamérica. Siglo XIX, págs. 613-628. Ciudad de México: Fondo de Cultura Económica.

Moniz Bandeira, Luiz Alberto. 2006. La formación de los Estados en la Cuenca del Plata. Buenos Aires: Grupo Editorial Norma.

Nabuco, Joaquim. 1897. Um estadista do Imperio. Río de Janeiro: H. Garnier. 1901. La Guerra del Paraguay. París: H. Garnier.

Prado, Maria Ligia Coelho. 2001. "O Brasil e a distante América do Sul”. Revista de História 145: 124-149.

Reis, Arthur Cézar Ferreira. 2001. A Amazônia e a Integridade do Brasil. Brasilia: Senado Federal.

Salles, Ricardo. 2013. Nostalgia imperial: escravidão e formação da identidade nacional no Brasil do Segundo Reinado, $2^{\mathrm{a}}$ ed. Río de Janeiro: Ponteio.

Santos, Luís Claudio Villafañe. 2016. "Duarte de Ponte Ribeiro: Defining the Territory of the Monarchy". En Brazilian Diplomatic Thought. Policymakers and Agents of Foreign Policy (1750-1964), editado por J. V. d. S. Pimentel, págs. 167-202. Brasilia: Fundação Getulio Vargas.

Sarmiento, Domingo Faustino. 2016. Argirópolis. Madrid: Biblioteca Saavedra Fajardo.

Silveira, Mauro César. 2015. "O inimigo na trincheira: a imagem dos aliados nas páginas dos jornais brasileiros e argentinos na guerra contra o Paraguai”. Història: Debates e Tendências 15 (2): 307-320.

Sodré, Nelson Werneck. 1983. Evolución social y económica del Brasil. San Pablo: Martins Fontes. 
Souza, Maurício Severo de. 2013. “A relação entre Igreja e Estado no Brasil do século XIX nas páginas de O Novo Mundo (1870-1879)”. Sacrilegens 10 (2): 48-62.

Torres, Miguel Gustavo de Paiva. 2011. O Visconde do Uruguai e sua atuação diplomática para a consolidação da política externa do Império. Brasilia: Fundação Alexandre de Gusmão. 